\section{Sustained response to targeted therapies in a patient with pulmonary hypertension owing to Langerhans cell histiocytosis}

\author{
Aykun Hakgör (D), Hacer Ceren Tokgöz ${ }^{1}$ (D) Özgür Yaşar Akbal1 ${ }^{1 D}$,

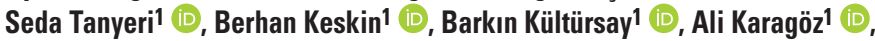 \\ Cihangir Kaymaz ${ }^{1}$ (D) \\ Department of Cardiology, Bingöl State Hospital; Bingöl-Turkey \\ 1Department of Cardiology, Kartal Koşuyolu High Speciality Training and \\ Research Hospital; Istanbul-Turkey
}

\section{Introduction}

Pulmonary hypertension (PH) in association with Pulmonary Langerhans Cell Histiocytosis (PLCH) is an uncommon pulmonary vascular disease classified in group $5 \mathrm{PH}$ according to currently available guidelines for the diagnosis and treatment of $\mathrm{PH}$. Oxygen support, diuretic treatment and lung transplantation are standard therapies for this disease. Generally, pulmonary arterial hypertension (PAH) targeted therapies are not considered to be beneficial in this subgroup of $\mathrm{PH}$.

\section{Case Report}

A 36-year-old female with a diagnosis of PLCH was referred to our tertiary center because of progressive dyspnea, and dry cough six years ago. She had a 12-year history of PLCH confirmed by lung wedge resection biopsy, and symptoms exacerbated within the past six months. She also had a history of smoking one packet of cigarettes a day for 18 years until cessation of smoking eight months ago.

She had peripheral cyanosis and severe dyspnea consistent with World Health Organization functional class IV status on admission. She could not walk within room. Physical examination revealed hoarseness, a marked right ventricular (RV) lift, accentuated pulmonary valve closure sound, a grade 2 diastolic murmur over the left second intercostal space, and bilateral rales in her lungs. Her vital signs at the time of admission were blood pressure of $100 / 70 \mathrm{~mm} \mathrm{Hg}$, heart rate of $110 \mathrm{bpm}$, and oxygen saturation on nasal oxygen support $(2 \mathrm{~L} / \mathrm{min})$ of $84 \%$. Electrocardiogram showed sinus rhythm with $\mathrm{P}$ pulmonale pattern, RV hypertrophy with systolic strain, and right axis deviation (Fig. 1). Chest radiography and computed tomography showed a combination of diffuse thick-walled, irregular-shaped cysts and reticulonodular shadows that were predominant in the mid and upper lobes of the lungs (Fig. 2). Pulmonary function tests revealed decreased forced vital capacity, forced expiratory volume in one second, and a $47 \%$ diffusing capacity of the lung for carbon monoxide. Her routine laboratory tests were normal. The

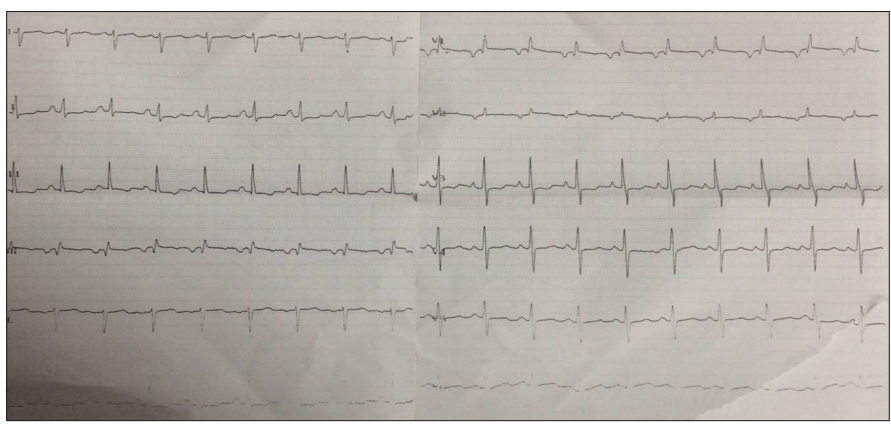

Figure 1. Electrocardiographic findings consistent with pulmonary hypertension

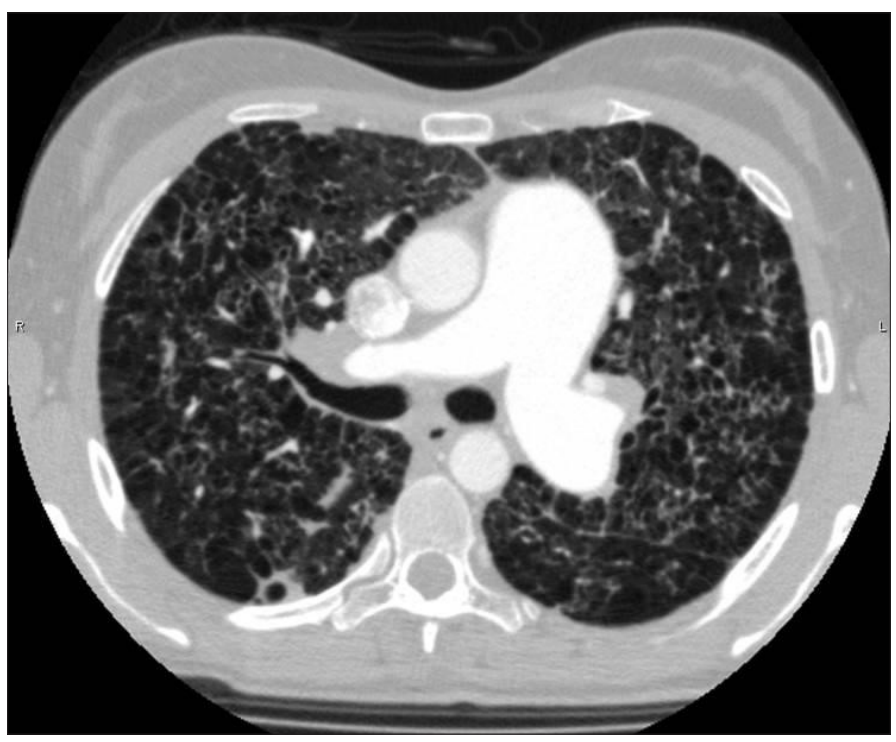

Figure 2. Chest $x$-ray findings of the patient

normal D-dimer level ruled out the acute pulmonary embolism. Her echocardiographic examination showed dilated right atrium and right ventricle, D-shaped interventricular septum, and normal left ventricular systolic functions. The M-mode measurement of tricuspid annular plane systolic excursion was $1.8 \mathrm{~cm}$, and the tissue velocity of tricuspid annular longitudinal systolic motion was $11 \mathrm{~cm} / \mathrm{sec}$. Pulmonary artery systolic and mean pressure estimates from tricuspid and pulmonary regurgitation jets were $95 \mathrm{~mm} \mathrm{Hg}$ and $55 \mathrm{~mm} \mathrm{Hg}$, respectively (Fig. 3a and 3b). Once all these non-invasive evaluations were done, we performed invasive right and left heart catheterization. Pulmonary artery mean and wedge pressures were $49 \mathrm{~mm} \mathrm{Hg}$ and $14 \mathrm{~mm}$ $\mathrm{Hg}$, respectively. Cardiac output was $3.5 \mathrm{~L} / \mathrm{min}$, and pulmonary vascular resistance was 13.7 Wood units. Vasoreactivity challenge with adenosine was negative. Hemodynamic characteristics of this patient were considered to be consistent with precapillary PH.

We started iloprost intravenous (i.v.) infusion $20 \mathrm{mcg} / \mathrm{min}$ and sildenafil $20 \mathrm{mg} 3 \times 1$ per oral (PO) therapies, and marked improvements in symptoms and overall clinical status were observed within the first few days following PAH-targeted 


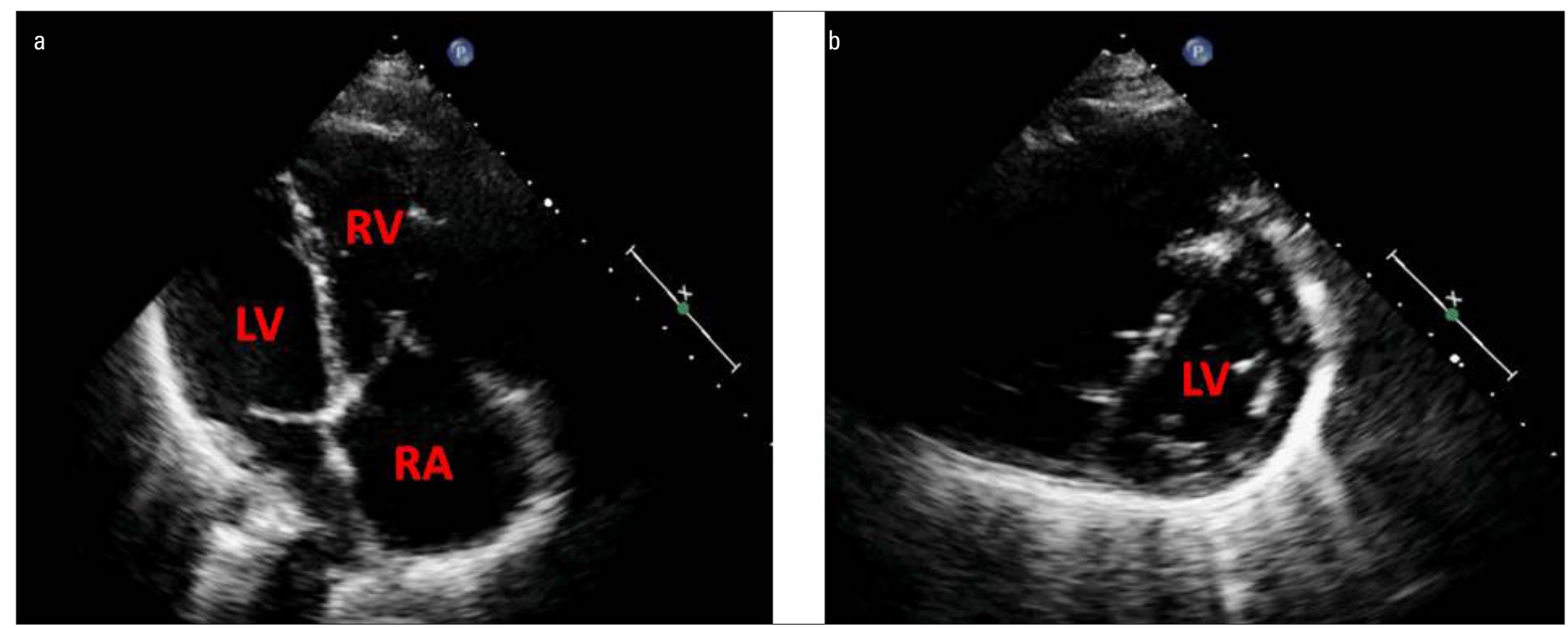

Figure 3. Apical four-chamber (a) and parasternal short axis (b) echocardiography showing enlarged right ventricle and D-shaped septum

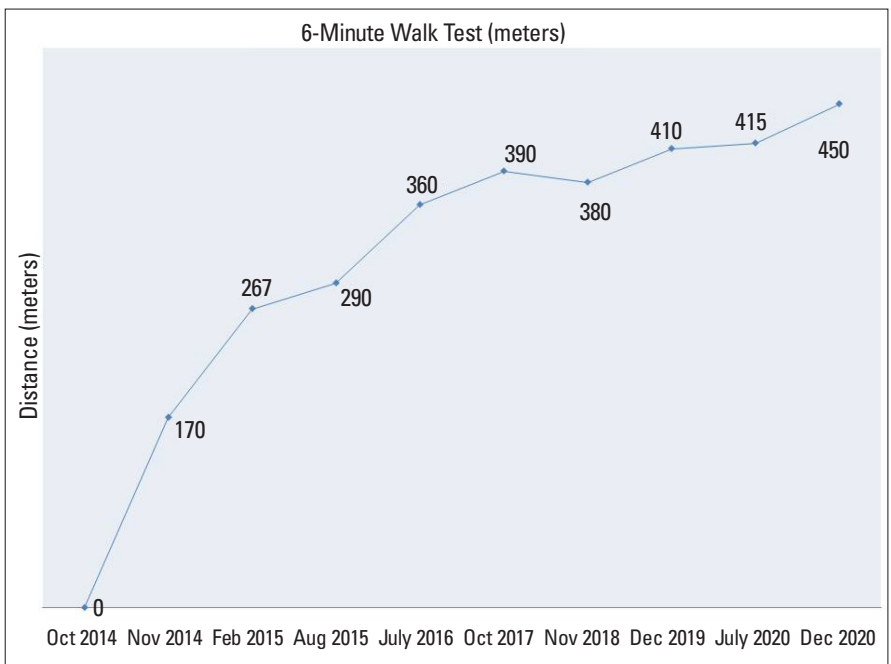

Figure 4. Longitudinal changes in six-minute walk distance

therapies. She became mobilized and was able to walk $170 \mathrm{~m}$ on the six-minute walk test (6MWT) on the $30^{\text {th }}$ day of hospitalization. It was decided to switch the in-hospital medications to treprostinil SC and tadalafil $20 \mathrm{mg} 1 \times 2$ as outpatient $\mathrm{PAH}$ therapies. The 6MWT distance increased to $250 \mathrm{~m}$ on the $40^{\text {th }}$ day of hospitalization, and the patient was discharged on these treatments. Progressive and sustained improvement in the clinical status of the patient was confirmed by control examinations at three-month intervals. During a 74-month period of treatment with tadalafil and treprostinil SC, the improvements in her functional class, 6MWT, and RV systolic functions measured by echocardiography were maintained (Fig. 4, and Fig. 5a-5c). Moreover, echocardiographic assessments revealed a slight decrease in pulmonary arterial pressures during the follow-up period. She did not experience any clinical worsening, and her current functional capacity was maintained at class 2 status.

\section{Discussion}

In our patient with severe $\mathrm{PH}$ because of $\mathrm{PLCH}$, a dramatic response to i.v. iloprost and $\mathrm{PO}$ sildenafil therapies was obtained during the in-hospital period, and the hemodynamic and clinical improvements have been maintained after switching to treprostinil SC -plus PO tadalafil -combination therapy at discharge. She tolerated high dose treprostinil $(52 \mathrm{mcg} / \mathrm{kg} / \mathrm{min})$ well, and her clinical status remained stable at the five-year follow-up.

The PLCH is a rare interstitial lung disease characterized by granulomatous lesions, including histiocytic Langerhans cells. These cells express S100 protein, CD1a, and langerin (CD207) and contain intracytoplasmic Birbeck granules (1). It is more common in smokers and the young adult population, and $25 \%$ of all patients are asymptomatic. Common symptoms are dry cough, dyspnea, pleuritic chest pain, fever, weight loss, and hemoptysis. Pulmonary function tests show restrictive, and sometimes obstructive pattern with decreased DLCO. Spontaneous pneumothorax may occur in $15 \%-25 \%$ of these patients. Bronchiolocentric nodules, irregular shaped cysts, reticulonodular opacities, interstitial wall thickening, and honeycombing can be seen on high resolution computed tomography. $\mathrm{PLCH}$ is definitively diagnosed by lung biopsy. Corticosteroids and some cytotoxic drugs such as cladribine are used to treat $\mathrm{PLCH}$. Older age, prolonged constitutional symptoms, multiorgan involvement, extensive cysts, honeycomb changes, severe decrease in diffusion capacity, obstructive lung function, prolonged treatment with steroids, and $\mathrm{PH}$ are considered as risk factors (1). The most important point is smoking cessation, which provides rapid improvement in clinical status $(2,3)$.

$\mathrm{PH}$ is a frequent and important complication of $\mathrm{PLCH}$, and it is currently classified as group $5 \mathrm{PH}$. Intrinsic vascular disease that consists of fibrotic changes and invasion by Langerhans cells is considered to be responsible for $\mathrm{PH}$ development in patients with PLCH (1, 4-6). There is limited data supporting the use of PAH specific medications in patients with group $5 \mathrm{PH}$, and they may be 


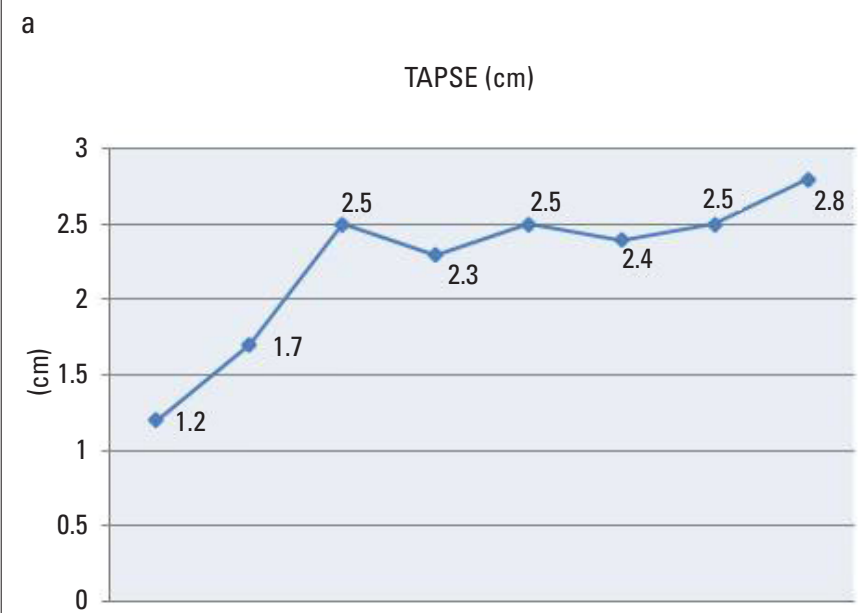

Oct 2014 Feb 2015 Aug 2015 July 2016 Mar 2017 Nov 2018 Dec 2019 July 2020 b

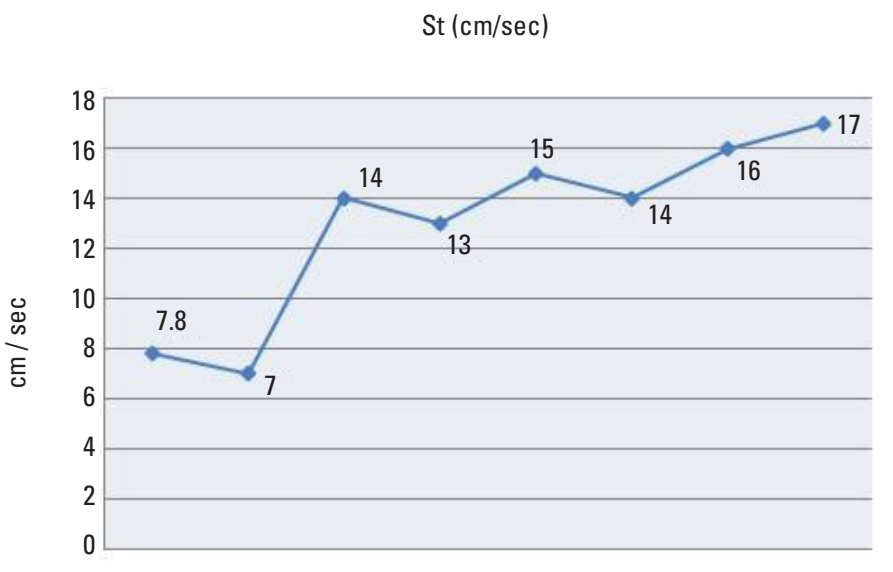

Oct 2014 Feb 2015 Aug 2015 July 2016 Mar 2017 Nov 2018 Dec 2019 July 2020

C

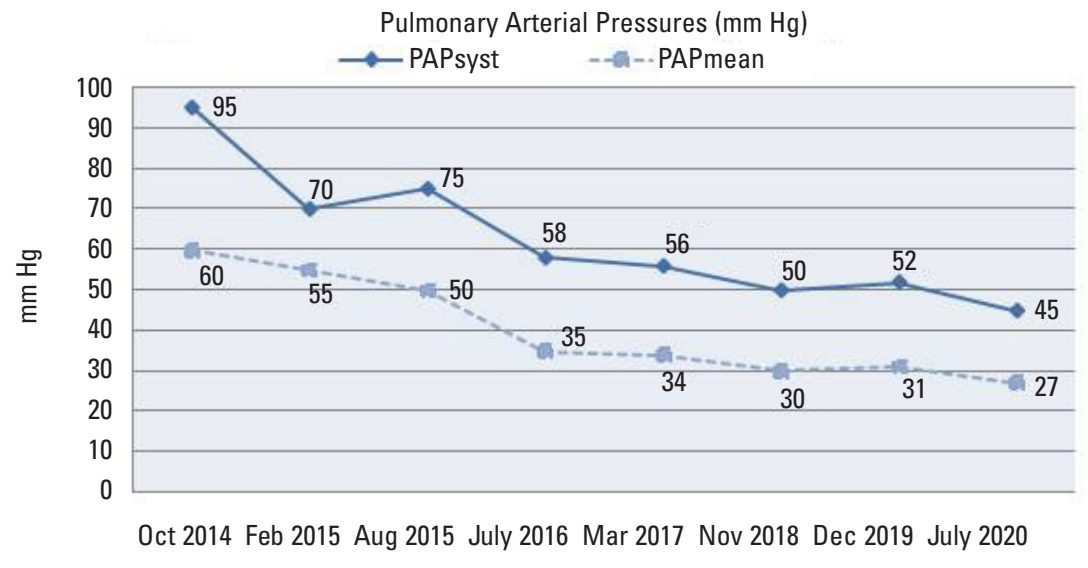

Figure 5. Longitudinal changes in tricuspid annular plane systolic excursion (a), tricuspid annular systolic tissue velocity (b), and pulmonary arterial systolic and mean pressures (c)

harmful in some cases. In most patients with group $5 \mathrm{PH}$, treatment should be focused on the underlying disease; and $\mathrm{PAH}$ therapies should be reserved for patients with severe pre-capillary $\mathrm{PH}$. According to the conventional approach, it is considered that PAH specific vasodilator therapies cause pulmonary edema, increase ventilation perfusion mismatch, exacerbate gas exchange, aggravate hypoxemia, and worsen clinical status in patients with $\mathrm{PH}$ because of lung diseases $(4,5)$. i.v. epoprostenol was tried in a very small number of patients and resulted in pulmonary edema (7). Conversely, some papers reported good clinical and hemodynamic outcomes with $\mathrm{PAH}$-specific drugs in these patients $(4-6,8)$. In addition, these drugs can be used as a bridging therapy to lung transplantation, although in the absence of prospective or head-to-head comparisons of PAH-specific therapies in $\mathrm{PLCH}$, endothelin receptor antagonists and phosphodiesterase-5 inhibitors seem to be effective $(8,9)$. In our patient, we observed sustained improvement in hemodynamic and clinical parameters with PAH treatments, and this benefit was obtained without any deterioration in oxygen saturation.
All patients with PLCH should be screened for $\mathrm{PH}$ with echocardiography in case of suspicion. If echocardiographic findings are consistent with $\mathrm{PH}$, confirmative invasive heart catheterization should be performed. This is necessary not only for hemodynamic diagnosis but also for the exclusion of post-capillary $\mathrm{PH}$ component, which may increase the risk of pulmonary edema with the initiation of PAH medications. Accordingly, PAH-specific drugs may be tried only in selected eligible patients.

\section{Conclusion}

$\mathrm{PH}$ in association with PLCH is an uncommon pulmonary vascular disease and have poor prognosis. In our case report, targeted dual-combination PAH therapy showed marked improvement in hemodynamic and clinical parameters.

Informed consent: Formal informed consent form was obtained from the patient. 


\section{References}

1. Roden AC, Yi ES. Pulmonary Langerhans Cell Histiocytosis: An Update From the Pathologists' Perspective. Arch Pathol Lab Med 2016; 140: 230-40. [Crossref]

2. Kinoshita Y, Watanabe K, Sakamoto A, Hidaka K. Pulmonary Langerhans Cell Histiocytosis-associated Pulmonary Hypertension Showing a Drastic Improvement Following Smoking Cessation. Intern Med 2016; 55: 491-5. [Crossref]

3. Epaud R, Ducou Le Pointe H, Fasola S, Ploussard S, Delestrain C, Sileo $\mathrm{C}$, et al. Cladribine improves lung cysts and pulmonary function in a child with histiocytosis. Eur Respir J 2015; 45: 831-3. [Crossref]

4. Nemoto K, Oh-Ishi S, Inui T, Nakazawa M, Hyodo K, Nakajima M, et al. Long-term improvement during tadalafil therapy in a patient with pulmonary hypertension secondary to pulmonary Langerhans cell histiocytosis. Respir Med Case Rep 2016; 18: 54-7. [Crossref]

5. May A, Kane G, Yi E, Frantz R, Vassallo R. Dramatic and sustained responsiveness of pulmonary Langerhans cell histiocytosis-associated pulmonary hypertension to vasodilator therapy. Respir Med Case Rep 2014; 14: 13-5. [Crossref]

6. Le Pavec J, Lorillon G, Jaïs X, Tcherakian C, Feuillet S, Dorfmüller P, et al. Pulmonary Langerhans cell histiocytosis-associated pulmo- nary hypertension: clinical characteristics and impact of pulmonary arterial hypertension therapies. Chest 2012; 142: 1150-7. [Crossref]

7. Fartoukh $\mathrm{M}$, Humbert $\mathrm{M}$, Capron $\mathrm{F}$, Maître S, Parent F, Le Gall C, et al. Severe pulmonary hypertension in histiocytosis X. Am J Respir Crit Care Med 2000; 161: 216-23. [Crossref]

8. Yoshida T, Konno S, Tsujino I, Sato T, Ohira H, Chen F, et al. Severe pulmonary hypertension in adult pulmonary Langerhans cell histiocytosis: the effect of sildenafil as a bridge to lung transplantation. Intern Med 2014; 53: 1985-90. [Crossref]

9. Weatherald J, Savale L, Humbert M. Medical Management of Pulmonary Hypertension with Unclear and/or Multifactorial Mechanisms (Group 5): Is There a Role for Pulmonary Arterial Hypertension Medications? Curr Hypertens Rep 2017; 19: 86. [Crossref]

Address for Correspondence: Dr. Aykun Hakgör, Bingöl Devlet Hastanesi, Kardiyoloji Kliniği, Bingöl-Türkiye Phone: +90 5362236191

E-mail: aykunhakgor@gmail.com

CCopyright 2021 by Turkish Society of Cardiology -

Available online at www.anatoljcardiol.com

DOI:10.5152/AnatolJCardiol.2021.49500 